\title{
Experimentally Simulating High Rate Composite Deformation in Tension and Compression: Polymer Bonded Explosive Simulant
}

\author{
Michael J. Kendall ${ }^{1}$ - Clive R. Siviour ${ }^{1}$
}

Received: 31 October 2014/Accepted: 11 April 2015/Published online: 21 April 2015

(C) Society for Experimental Mechanics, Inc 2015

\begin{abstract}
Characterizing the response of composite materials to high strain rate deformation is of great importance for a range of applications; however, the experiments required to do this are challenging. In order to be fully representative, specimens must be large, making it difficult to achieve mechanical equilibrium; furthermore diagnostic tools such as X-ray tomography and electron microscopy cannot be used on the required timescales of ca $10 \mu \mathrm{s}$. Many composites consist of a rate and temperature dependent polymer binder, with a filler that is independent of these parameters. In this paper, a simulation technique is applied, in which the high rate mechanical response of a composite is experimentally reproduced in low strain rate experiments by making use of the polymer time-temperature superposition principle. This is a novel application of time-temperature superposition to composite materials in order to experimentally replicate the high-rate response. In order to demonstrate this method on a model composite material, a particulate composite (polymer bonded sugar) and its binder are extensively characterized in compression, and the composite in indirect tension (Brazilian) tests, over a range of strain rates and temperatures. It is then shown that by reducing the temperature, low rate experiments can be performed which faithfully replicate the high rate data, opening up the opportunity for more extensive research programs combining mechanical testing and microstructural characterization of these materials.
\end{abstract}

Clive R. Siviour

clive.siviour@eng.ox.ac.uk

1 Department of Engineering Science, University of Oxford, Parks Road, Oxford OX1 3PJ, UK
Keywords Particle-reinforced composites - Mechanical properties $\cdot$ Stress/strain curves $\cdot$ High strain rate characterisation

\section{Introduction}

\section{Experimental Simulation of High Rate Deformation}

The high strain rate properties of composite materials, often consisting of a relatively rate independent filler in a rate dependent binder, are of increasing importance in a range of applications in the medical, automotive, aerospace and defense industries. However, while high strain rate characterization experiments may be performed, understanding the underlying causes of the observed behavior, in particular with reference to the microstructure, is made difficult by the lack of diagnostic tools available which can operate on a sub millimeter length-scale and a microsecond timescale. Hence, the development of experimental methods to understand and simulate high strain rate behavior (i.e. using microscopic diagnostic equipment applied to experiments with longer timescales) would be of significant benefit to the composites community.

To perform an experimental simulation of high rate behavior of composites using low rate experiments, the use of time-temperature superposition is expected to provide a powerful tool. This has been used by a number of authors [1-5] to understand the yield stress of polymers at rates up to ca. $10^{4} \mathrm{~s}^{-1}$; however, Kendall and Siviour [6] were the first to apply this technique to simulating the large-strain true stress-true strain behaviour of a polymer at high rates. The authors simulated the high rate behaviour of a polymer (polyvinyl chloride, PVC, with $20 \mathrm{wt} \%$ plasticiser) through low rate experiments that started at reduced temperatures, 
before using temperature profiles to account for the adiabatic heating effect in high rate deformation. The methodology used in the aforementioned research forms the basis of the current paper. Further research was performed on polycarbonate (PC) and poly(methyl methacrylate) (PMMA), showing the power of this technique to understand rate dependence in a range of polymers [7].

Following the success of this approach, the current paper addresses the high rate characterisation of composite materials. In particular, time-temperature superposition is applied to a particulate composite, a polymer bonded explosive simulant (PBS), in tension, via Brazilian testing, and in compression. Characterisation of both the composite and the binder was performed via dynamic mechanical and thermal analysis (DMA) and compression experiments at different rates and temperatures. Then, experiments were performed demonstrating that quasi-static experiments at reduced temperatures can indeed replicate the high rate, room temperature, response in both loading configurations. This paper highlights an important step in dynamic materials characterisation: we can take materials which are difficult to test at high rates of deformation, such as composites, and using time-temperature superposition, perform experiments that will allow them to be understood at the microscopic-scale: an understanding that is unachievable with current diagnostic tools.

\section{PBXs, PBSs, and Brazilian Testing}

Although this paper is mainly concerned with the use of PBSs as a model material for the simulation technique, a brief overview of their use and previous research on their mechanical properties is given here.

Polymer bonded explosives (PBXs) are seen in a wide range of applications, from the central explosive charge in standard armaments to rocket propellants. In armaments, PBXs typically contain 2-10\% (by mass) of polymer, or up to $40 \%$ for rocket propellants: the polymer acts as a load mitigator to improve safety in in storage and handling and is typically a rubbery material (e.g. hydroxyl-terminated polybutadiene, HTPB). The second component of the PBX typically consists of an explosive in the form of small crystals, ranging from $\sim 10$ to $500 \mu \mathrm{m}$ diameter [8]. For PBX simulants, such as those used in this study, the explosive-substitute is typically sugar crystals (mainly due to comparable particle sizes and mechanical behavior, but also because they are non-toxic).

Bowden and Yoffe [9, 10] were among the first to study ignition mechanisms in explosives and concluded that explosive reactions begin at localized 'hot spots.' Further investigations have offered insight into impact ignition, and its two-step process: initiation and propagation [11, 12].
The use of a binder suppresses both of these steps, and hence considerably reduces the sensitivity of the explosive.

Swallowe and Field [13] studied the mechanical properties and sensitivity of PBXs and showed the importance of the polymer binder. Surface, thermal, and mechanical properties must all be considered when choosing a binder material.

Palmer et al. [8] examined a wide range of PBXs with different compositions in tension at quasi-static strain rates, with the aim of optimizing the materials. Brazilian tests (the 'indirect tensile test'), which were originally introduced by Carneiro and Barcellos [14], were used, combined with optical techniques to measure the twodimensional in-plane displacement fields. Advantages of this technique were cited as the relatively small specimens (e.g. cylindrical specimens of $10 \mathrm{~mm}$ diameter $\times 4 \mathrm{~mm}$ thickness), and that the complicated gripping methods required to perform tensile tests on composites were avoided. This experimental test method is described in greater detail in Awaji and Sato [15]. In particular, the equation used to calculate tensile stress at the center of a test specimen is:

$\sigma=\frac{2 P}{\pi D_{s} t_{s}}\left(1-\left(\frac{b}{R_{s}}\right)^{2}\right)$

where $P$ is the applied compressive load, $D_{s}$ and $t_{s}$ the diameter and thickness of the specimen respectively, $R_{s}$ is the radius of the specimen, and $b$ is the width of the contact between the specimen and the anvils.

Over the past 15 years, a wide range of investigations of the mechanical properties of polymer bonded explosives (PBXs), and their simulants (PBSs), under high rate deformation have been seen in literature [3, 16-25], often using Brazilian testing to study tensile behavior (e.g. [26, 27]). These investigations found a clear rate-, and temperature-, dependency in the apparent elastic modulus, yield, and post-yield behavior. Williamson et al. [3] and Thompson et al. [24] presented the result of successful time-temperature superposition in PBXs. Results such as these indicate that the experimental simulation method in "Experimental Simulation of High Rate Deformation" section can be applied to these materials. This is the subject of the current paper.

\section{Experimental Method}

\section{Materials}

The PBS used in this paper consisted of $83 \%$ caster sugar as the filler, of both coarse $(400-600 \mu \mathrm{m})$ and fine $(10-110 \mu \mathrm{m})$ diameters, in an HTPB binder. Both the PBS and the binder were characterized and the pure HTPB is the 
same formulation as used in the PBS. Both materials were manufactured at the high explosives research and development (HERD) facility of the Energetic Materials Branch of Air Force Research Laboratory, in Eglin, FL, USA.

\section{Dynamic Mechanical and Thermal Analysis}

Dynamic mechanical and thermal analysis (DMA) testing was conducted with a TA Instruments Q800 DMA. Tests were performed in dual cantilever configuration at 1,10 and $100 \mathrm{~Hz}$, on PBS over the temperature range -150 to $25{ }^{\circ} \mathrm{C}$, and on HTPB over the temperature range -150 to $-15^{\circ} \mathrm{C}$, so that each material was taken well below the glass transition. Rectangular samples were used of dimensions $60 \times 12.5 \times 2.5 \mathrm{~mm}$.

\section{Compression Testing}

Uniaxial compression testing was performed at temperatures from -110 to $20{ }^{\circ} \mathrm{C}$ at a strain rate of $10^{-2} \mathrm{~s}^{-1}$, and rates from $10^{-3}$ to $4800 \mathrm{~s}^{-1}$ at $20^{\circ} \mathrm{C}$. Test specimens were $4 \mathrm{~mm}$ long and $6 \mathrm{~mm}$ in diameter for the PBS, $8 \mathrm{~mm}$ diameter for the HTPB. Quasi-static compression experiments were performed on a commercial load frame (Instron) with an environmental chamber, using a standard liquid nitrogen attachment to achieve low temperatures and a clip gage attached to the loading anvils to measure the specimen displacement, from which strain was calculated. The temperature control was accurate to $\pm 2{ }^{\circ} \mathrm{C}$, as measured by both the environmental chamber feedback thermocouple and a second thermocouple attached to the loading anvil close to the specimen. Tests conducted for the experimental simulation of high rate behavior were also performed at $10^{-2} \mathrm{~s}^{-1}$. For high rate experiments $\left(>10^{3} \mathrm{~s}^{-1}\right)$ on the PBS, a $12.7 \mathrm{~mm}$ diameter magnesium alloy (AZM) split-Hopkinson pressure bar (SHPB) [28, 29] was used. However, the very low strength of the HTPB prevented data from being obtained using this system, and instead a bar system was developed which used lead zirconium titanate $(\mathrm{PZT})^{1}$ stress gauges to directly measured the forces at the bar-specimen interfaces. This method for testing soft materials at high rates of deformation is an improvement to the Quartz crystal methodology of Chen et al. [30], and is discussed further in in Kendall et al. [31].

\section{Tension Testing via Brazilian Disc Tests}

Quasi-static Brazilian tests were performed over a temperature range from -45 to $20^{\circ} \mathrm{C}$; high rate tests were

\footnotetext{
${ }^{1}$ PZT manufacturer was APC International Ltd., in Mackeyville, Pennsylvania, USA. The PZT used in this study has a piezoelectric constant of $400 \times 10^{-12} \mathrm{C} / \mathrm{N}$ (or $\mathrm{m} / \mathrm{V}$ ), provided by manufacturer.
}

performed at $20{ }^{\circ} \mathrm{C}$ over a range of deformation speeds. Specimens had a diameter of $10 \mathrm{~mm}$ and a thickness of $4 \mathrm{~mm}$. In order to perform the tests, curved platens were manufactured to a radius of curvature of $6 \mathrm{~mm}$ from a Titanium alloy (Ti-6Al-4V). In previous studies this combination of specimen and anvil dimensions has been shown to give a $b / R_{S}$ ratio greater than 0.27 , which is required in order to allow the tensile strength of the specimen to be independent of $b / R_{s}$ [15]: the ratio of observed compression platen contact width $(b)$ and specimen radius $\left(R_{s}\right)$ in these experiments was calculated to be 0.38 . Quasi-static experiments were performed using two commercial loading stages: a stage manufactured by Deben UK Ltd, using Peltier cooling, and the Instron load frame discussed above. High rate experiments were performed using the SHPB apparatus with Ti-6Al-4V bars. In quasi-static experiments, images of the specimen deformation were captured using a Nikon D3100 DSLR camera. At high rates, a Photron SA5 high speed camera was used with an exposure time of $1 \mu$ s and interframe time of $10 \mu \mathrm{s}$, triggered via the input bar's strain gage. The image size for the Phantom was $256 \times 224$ pixels. In all cases, tensile strains were calculated from full field displacement data obtained via digital image correlation (DIC) performed using DaVis 7.2 DIC Software, with a window (subimage) size of $16 \times 16$ pixels; strains were calculated as described below. A more detailed description of the DIC method may be found in Sutton et al. [32].

In summary, the parameters used to calculate the tensile stress at the center of the test specimen in Eq. 1 were as follows: $b=1.9 \mathrm{~mm} ; D_{s}=10 \mathrm{~mm} ; t_{s}=4 \mathrm{~mm} ; R_{s}=5 \mathrm{~mm}$; $(b / R)=0.38$.

\section{Results and Analysis}

\section{Dynamic Mechanical and Thermal Analysis}

The HTPB and PBS DMA test results are summarized in Fig. 1a, b. The $\alpha$ (glass) transition of the HTPB is very low at approximately $-85^{\circ} \mathrm{C}$, with the beginning of a broad $\beta$ transition starting at approximately $-100{ }^{\circ} \mathrm{C}$ (moving from high to low temperatures), in the $100 \mathrm{~Hz}$ curve. The data allow shift factors to be calculated: $6{ }^{\circ} \mathrm{C} / \mathrm{decade}$ for the $\alpha$ transition and $20^{\circ} \mathrm{C} / \mathrm{decade}$ for the $\beta$ transition. The $\alpha$ transition of this HTPB is approximately $25^{\circ} \mathrm{C}$ lower than in a previous study in the literature $\left(-85\right.$ vs. $\left.-60{ }^{\circ} \mathrm{C}\right)$, and the $\alpha$ shift factor is $\sim 4{ }^{\circ} \mathrm{C} /$ decade strain rate lower (6 vs. $10{ }^{\circ} \mathrm{C} /$ decade strain rate). In addition, the glass transition in the HTPB of this study spans approximately $25^{\circ} \mathrm{C}$, versus a range of over $50{ }^{\circ} \mathrm{C}$ [19]. Hence, the HTPB in this study remains rubbery to lower temperatures and is much more sensitive to temperature, or rate, changes in the glass transition region. These differences in the properties of 
(a)

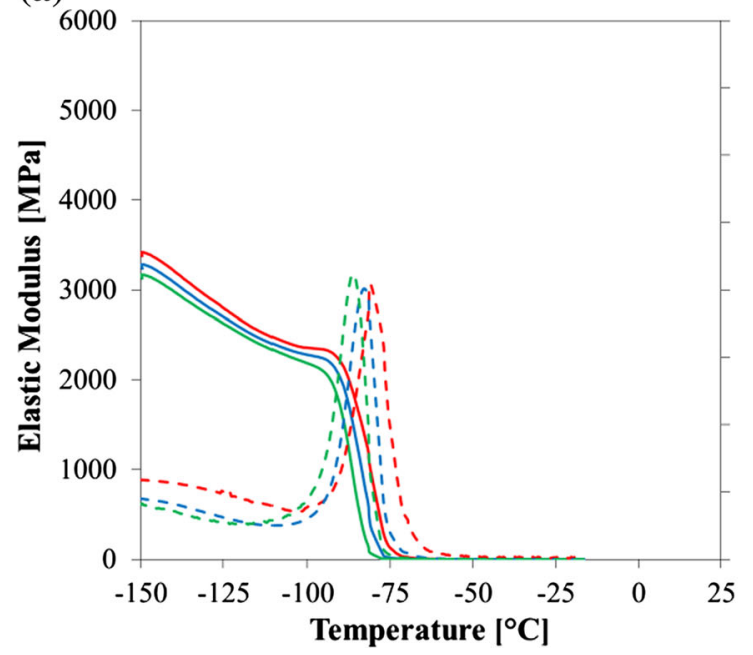

(b)

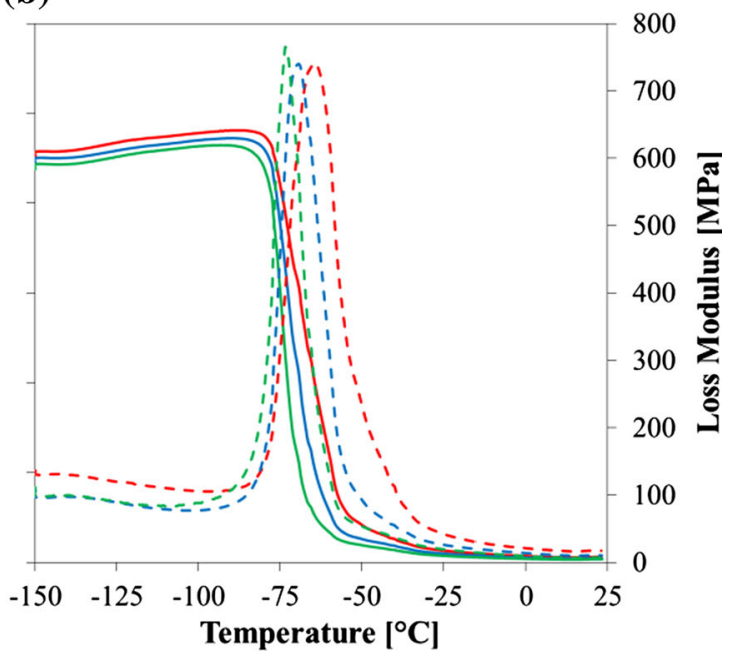

Fig. 1 a HTPB and b PBS: elastic modulus (solid lines) and loss modulus (dashed lines) as a function of temperature at $1 \mathrm{~Hz}\left(0.032 \mathrm{~s}^{-1}\right.$ green), $10 \mathrm{~Hz}\left(0.32 \mathrm{~s}^{-1}\right.$ blue $)$, and $100 \mathrm{~Hz}\left(3.2 \mathrm{~s}^{-1}\right.$ red $)$ (Color figure online)

HTPB observed between studies are not surprising, as these properties are dependent on details of the manufacturing. However, for the current study, it is important to note that the same HTPB formulation was used in the PBS material as in the pure HTPB characterization.

The PBS also presents rubbery behavior with an $\alpha$ transition at approximately $-70{ }^{\circ} \mathrm{C}$, shifting at $10{ }^{\circ} \mathrm{C}$ per decade of strain rate, with again the possibility of a $\beta$ transition at lower temperatures. Because the filler has a modulus many orders of magnitude higher than the binder, all the applied deformation is taken up in the binder, meaning that for a given magnitude and frequency of oscillation, the effective strain rate in the binder is higher, and the $\alpha$ transition temperature increases, compared to the pure HTPB. Comparing again to literature data [19], from a $66 \%$ (vs. $83 \%$ in this study) caster sugar PBS, the $\alpha$ transition of the PBS in the current research is approximately $-60{ }^{\circ} \mathrm{C}$ lower ( -70 vs. $-10{ }^{\circ} \mathrm{C}$ ), and the $\alpha$ shift factor is $\sim 20^{\circ} \mathrm{C} /$ decade strain rate lower $\left(10\right.$ vs. $30^{\circ} \mathrm{C} / \mathrm{decade}$ strain rate). In addition, the glass transition in the PBS in this study spans approximately 45 , $20{ }^{\circ} \mathrm{C}$ larger than its binder, but over $55^{\circ} \mathrm{C}$ less than that found in Siviour et al. [19]. In conclusion, the PBS in this study, due to the much more rubbery HTPB binder, is more rubbery than a PBS with $66 \%$, significantly less, crystalline filler material. Regardless of the differences seen in the HTPB binder used in this study, the overall behavior of transitions broadening as a result of the added explosive or simulant, is consistent with observations in literature [3, 21].

\section{Compression Testing of HTPB and PBX Simulant}

Uniaxial compression testing results are summarized in Figs. 2, 3, 4 and 5. In the quasi-static tests (Fig. 2), all
HTPB specimens deformed in a rubbery manner at temperatures above $-90{ }^{\circ} \mathrm{C}$, with a glassy region beginning sharply below this temperature. The behavior at $-100{ }^{\circ} \mathrm{C}$ presents interesting characteristics: because these tests are centered around the glass transition temperature, slight changes in temperature bring about large changes in modulus, yield stress, and post-yield behavior; hence, even when testing at nominally the same temperature $\left(-100{ }^{\circ} \mathrm{C}\right)$ a wide range of yield stresses is observed from roughly $10 \mathrm{MPa}$ to about $35 \mathrm{MPa}$. The HTPB true stress-true strain behavior demonstrates increasingly glassy polymer characteristics at lower testing temperatures: for example, a dramatic post-yield softening of about $25 \mathrm{MPa}$ is observed at $-110{ }^{\circ} \mathrm{C}$, and about $10 \mathrm{MPa}$ in two of the experiments at $-100{ }^{\circ} \mathrm{C}$. Similar behavior is observed in the PBS (Fig. 4), e.g. softening of $10 \mathrm{MPa}$ is observed in true stress-true strain behavior at $-80{ }^{\circ} \mathrm{C}$, although the apparent yield in the PBS is broader than the yield in the HTPB.

The $\alpha$ transition in the HTPB (Fig. 2) is between -90 and $-100{ }^{\circ} \mathrm{C}$ (at $10^{-2} \mathrm{~s}^{-1}$ ) which is reasonably consistent with the DMA data presented in Fig. 1a. Comparison between PBS data sets is more interesting, in that the quasistatic compression data at room temperature appear to show glassy behavior (Fig. 4), although there is no apparent contribution of the glass $(\alpha)$ transition at these rates and temperatures $\left(20^{\circ} \mathrm{C}\right)$ in DMA data (Fig. 1b) - this is consistent with a conclusion that the observed behavior is most likely due to gradual debonding of the crystals from the binder as observed by Siviour et al. [19].

Comparing rate dependencies of the HTPB (Fig. 3) and the PBS (Fig. 5), in the PBS, yielding is seen in all true stress-true strain rate dependent behavior, where in HTPB, the response continues to be rubbery even at high strain rates 
(a)

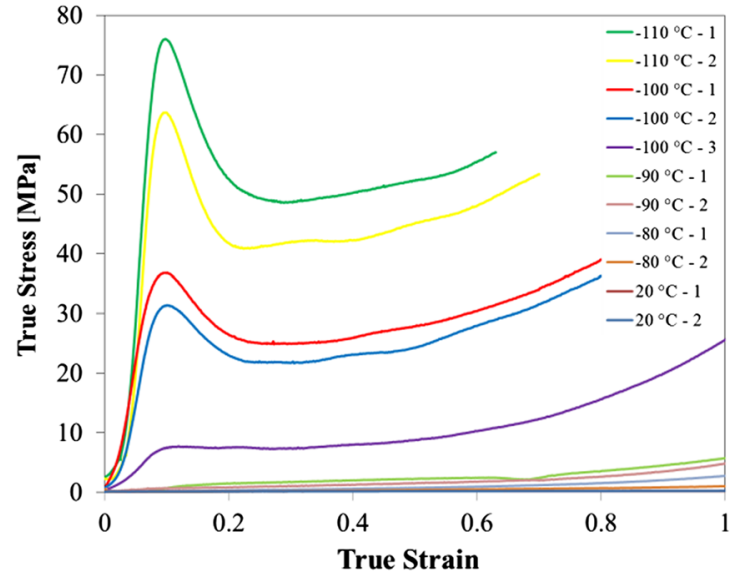

(b)

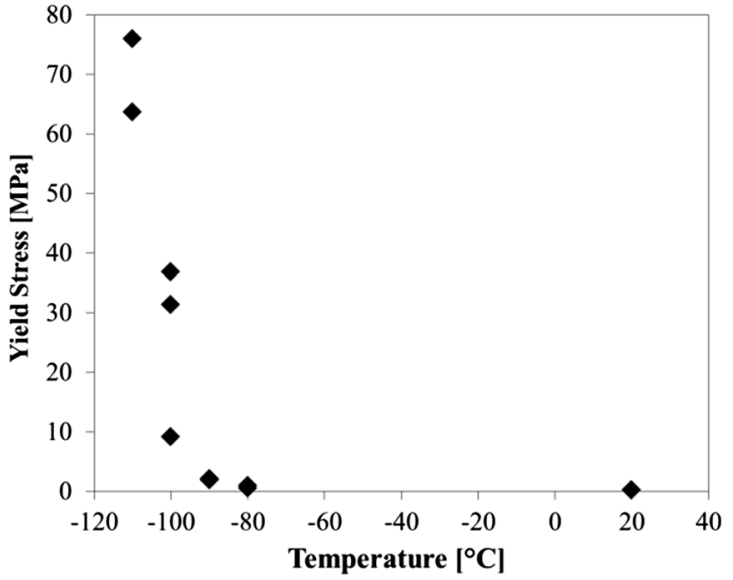

Fig. 2 HTPB a true stress-true strain and $\mathbf{b}$ yield stress as a function of temperature at a rate of $10^{-2} \mathrm{~s}^{-1}$ in compression. Note for $\mathbf{b}$ true stress data at 0.1 true strain is reported for the yield stress at $-90{ }^{\circ} \mathrm{C}$ and above

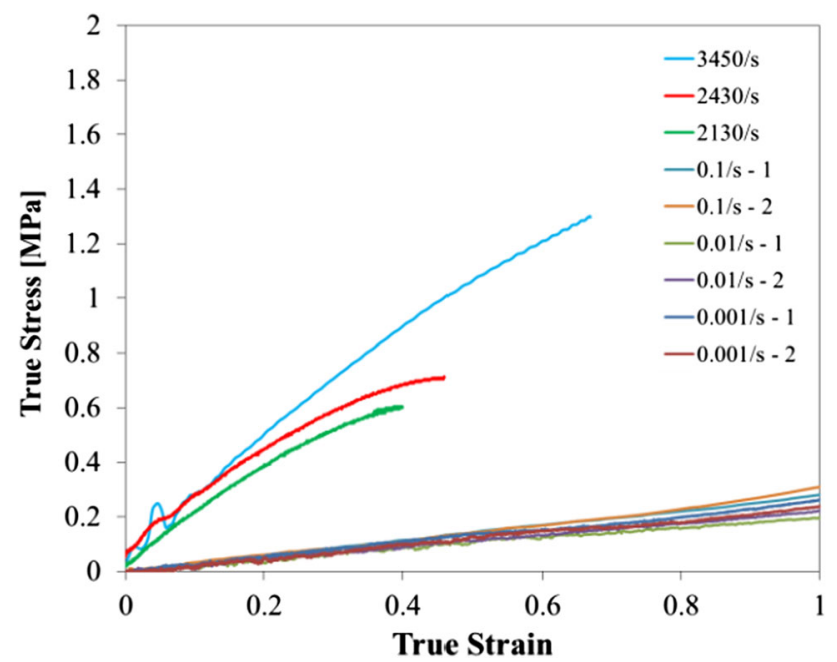

Fig. 3 Representative true stress-true strain behavior of HTPB as a function of strain rate $\left(10^{-3}-3450 \mathrm{~s}^{-1}\right)$ at an ambient temperature of $20{ }^{\circ} \mathrm{C}$ in compression

(up to $3450 \mathrm{~s}^{-1}$ ). The dependence on strain rate of the PBS shows again the effect of the $\alpha$ transition at elevated strain rates, the fact that this transition is apparent in these data but not those from the HTPB is to be expected from the difference into strain rate sensitivity between the two materials seen earlier in the DMA shift factors, coupled with the higher temperature of the transition in the PBS DMA data.

\section{Tension Testing on a Composite (PBS) via Brazilian Testing}

Results from Brazilian tests performed on PBS are summarized in Fig. 6. As for the compression experiments, Brazilian tests at a deformation speed of $10^{-6} \mathrm{~m} \mathrm{~s}^{-1}$ were performed in a commercial load frame with an environmental chamber to access sub-ambient temperatures, whilst experiments at higher speeds were performed in a split-Hopkinson bar. In Fig. 6a, the high rate behavior demonstrates an expected (pseudo-) glassy behavior, due to the system going through its alpha transition, and debonding of the polymer from the matrix, where an increase in strength is observed with increasing strain rate. In the dynamic experiments, dynamic equilibrium was observed from about $20 \mu$ s after the start of testing. Figure $6 \mathrm{~b}$ shows the temperature independence of the material above $\sim-15^{\circ} \mathrm{C}-$ consistent with Fig. $1 b$ where the $\alpha$ transition is observed at about $-25{ }^{\circ} \mathrm{C}$. Temperature dependence is observed at lower temperatures.

Further analysis will now be presented from applying the DIC technique to the experiment at $6 \mathrm{~m} \mathrm{~s}^{-1}$ to calculate tensile behavior in the specimen. The images are shown in Fig. 7. The images were analyzed using commercial DIC software (DaVis) to produce displacement fields over the whole specimen surface (see [32] for a description of the DIC technique). Taking a line along the centre of the specimen, in the direction transverse to the loading, the displacement in this direction was plotted against position for each frame, see Fig. 8 for examples. The gradient of this line was therefore the mean tensile strain in the test. The same method was used to produce tensile strain from quasi-static experiments, but images were acquired using a Nikon D3100 SLR camera. The resultant true strain-time results are presented in Fig. 9a. The tensile strain rate was calculated to be approximately $850 \mathrm{~s}^{-1}$. The true stress-true strain behavior of this specimen is shown in Fig. $9 \mathrm{~b}$.

\section{Experimental Simulation of High Rate Composite Behavior}

Using the data obtained so far, the experimental simulation method described previously by the authors [6] was used to 
(a)

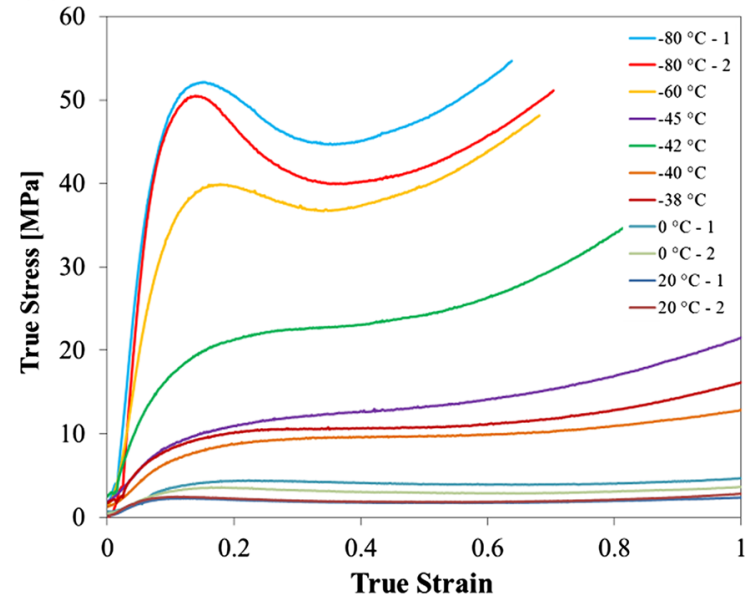

(b)

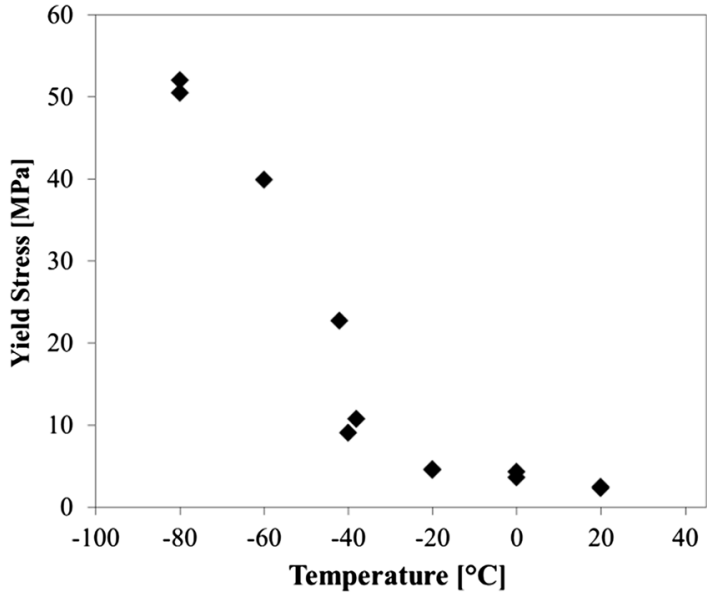

Fig. 4 PBS a true stress-true strain behavior and $\mathbf{b}$ yield stress behavior as a function of temperature $\left(-80\right.$ to $\left.+20^{\circ} \mathrm{C}\right)$ at a rate of $10^{-2} \mathrm{~s}^{-1}$ in compression

(a)

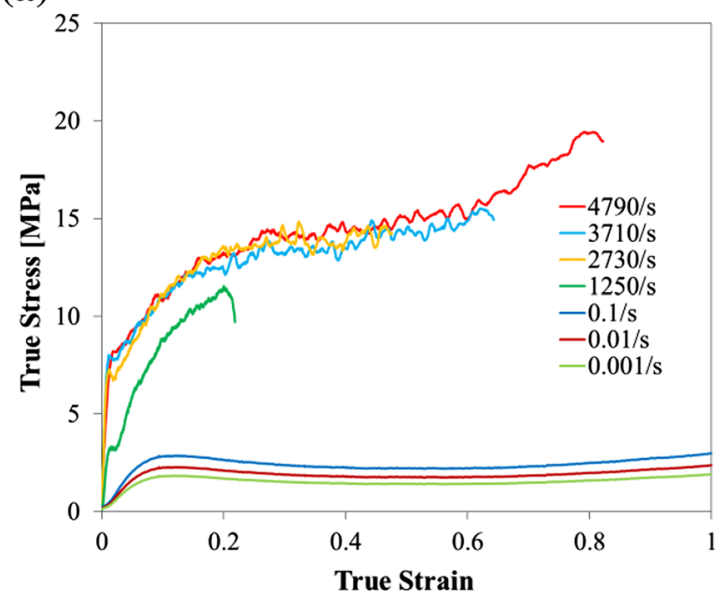

(b)

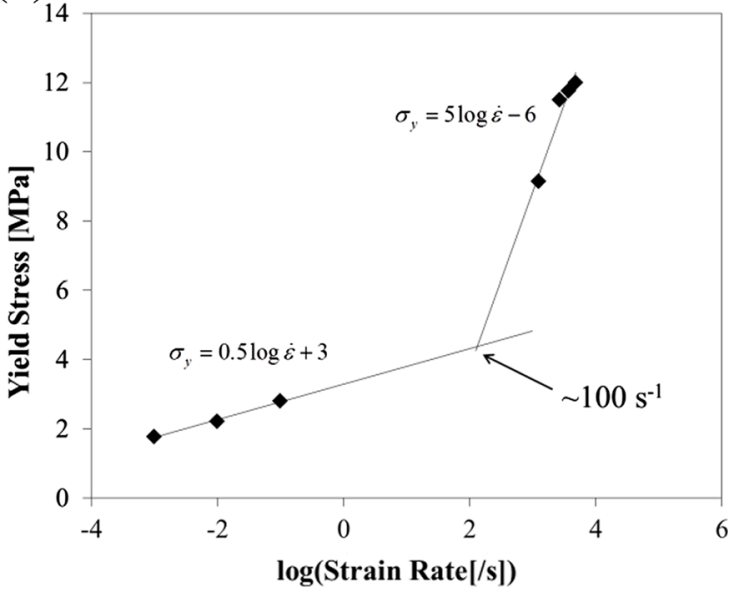

Fig. 5 Representative a true stress-true strain and $\mathbf{b}$ yield stress behavior of PBS as a function of strain rate $\left(10^{-3}-4790 \mathrm{~s}^{-1}\right)$ in compression at $20{ }^{\circ} \mathrm{C}$

replicate the room temperature high rate behavior of the PBS in compression and tension by low rate experiments at reduced temperatures.

From the stress-strain data in the high rate experiment, the expected temperature rise in the specimen was calculated, and is also shown in Fig. 8b. Assuming full conversion of work into heat and adiabatic conditions, the rise is less than $1 \mathrm{~K}$ (see footnote ${ }^{2}$ for material properties used, and Fig. 9b). Hence, there is no requirement to take account of this rise when using time-temperature superposition on this material, although it is noted that whilst this

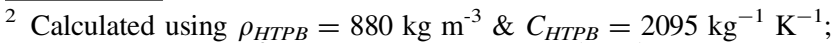
$\rho_{\text {sugar }}=1586 \mathrm{~kg} \mathrm{~m}^{-3} \& C_{\text {sugar }}=1245 \mathrm{~J} \mathrm{~kg}^{-1} \mathrm{~K}^{-1}$; giving (from the binder-crystal ratio) $\rho_{P B S}=1466 \mathrm{~kg} \mathrm{~m}^{-3}$ and $C_{\text {sugar }}=$ $1390 \mathrm{~J} \mathrm{~kg}^{1} \mathrm{~K}^{-1}$. calculation assumes the temperature to be evenly distributed through the specimen, it is likely that at very high rates the heat generated is concentrated in the binder, as this is the component of the PBS which experiences the majority of the deformation, and there is a timescale associated with diffusion of heat into the filler.

The two experiments simulated were chosen to be at similar strain rates: $1250 \mathrm{~s}^{-1}$ in compression and $850 \mathrm{~s}^{-1}$ in tension, in particular, this rate was chosen because the influence of the $\alpha$ transition is readily observed; the test temperature chosen for the simulation experiments was $-45^{\circ} \mathrm{C}$. The results of the two compression experiments: $1250 \mathrm{~s}^{-1}$ at room temperature and $10^{-2} \mathrm{~s}^{-1}$ at $-45^{\circ} \mathrm{C}$ are presented in Fig. 10. The low rate experiment faithfully captures the high rate behavior. 
(a)

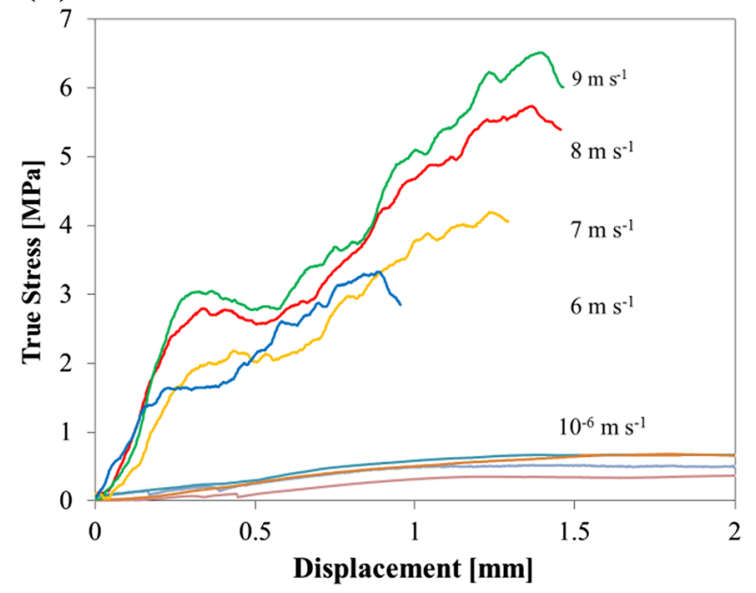

Fig. 6 Tensile true stress-time response of PBS: dependence on (a) deformation rate at $20{ }^{\circ} \mathrm{C}$, and (b) temperature at $10^{-6} \mathrm{~m} \mathrm{~s}^{-1}$. Tensile stress was calculated using Eq. 1 using parameters in the text. (b)

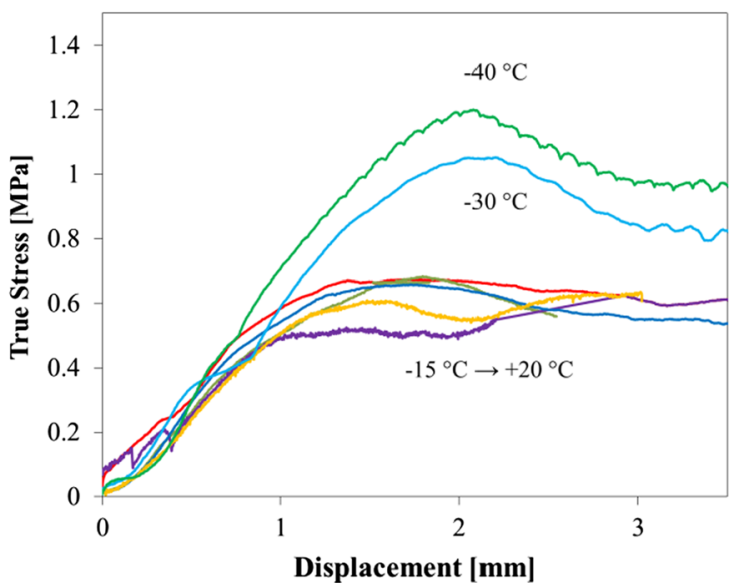

Data at $10^{-6} \mathrm{~m} \mathrm{~s}^{-1}$ from screw-driven load frame, data at 6, 7, 8 and $9 \mathrm{~m} \mathrm{~s}^{-1}$ from split-Hopkinson bar
Fig. 7 Initial high speed images during Brazilian tension testing of PBS at $6 \mathrm{~m} \mathrm{~s}^{-1}$. In each row, the times increase in value by $10 \mu$ s reading left-toright

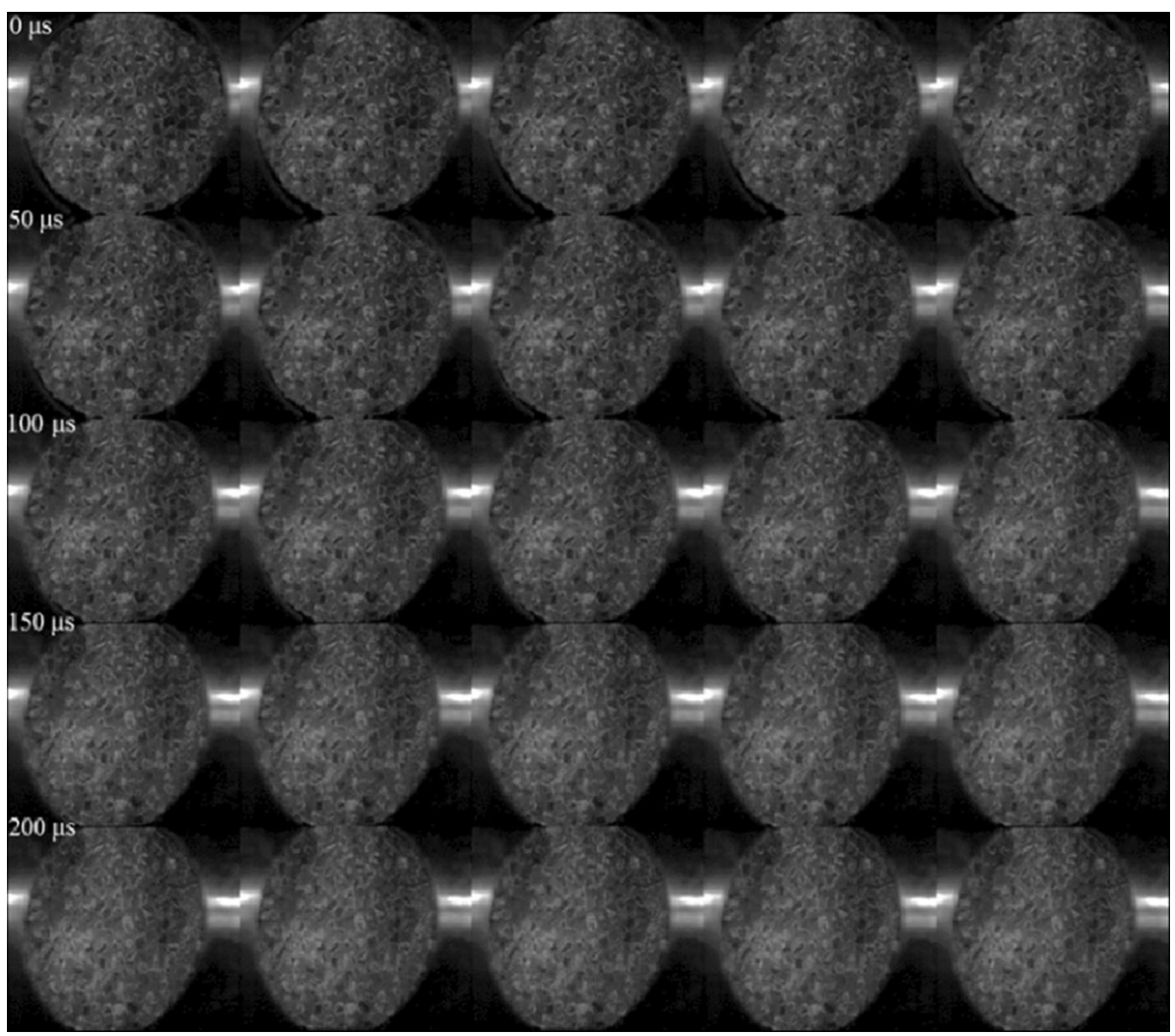

The equivalent data in tension are shown in Fig. 11. As in the compression experiments, good agreement between simulation and experiment was observed. The slight 'yielding' in both results at $\sim 3 \%$ true strain is understood to be the effect of debonding of the sugar crystals in the PBS. Compared to the apparent compressive yield stress, the apparent yield in tension is significantly lower (3 $\mathrm{MPa}$ in tension, and $12 \mathrm{MPa}$ in compression), also consistent with debonding between the binder and the filler.

These data show the key result in this paper: we can use time-temperature superposition to replicate the high rate behavior of a particulate composite in tension, as well as in compression. These results in several ways capture a major objective of this program of research into the experimental 
(a)

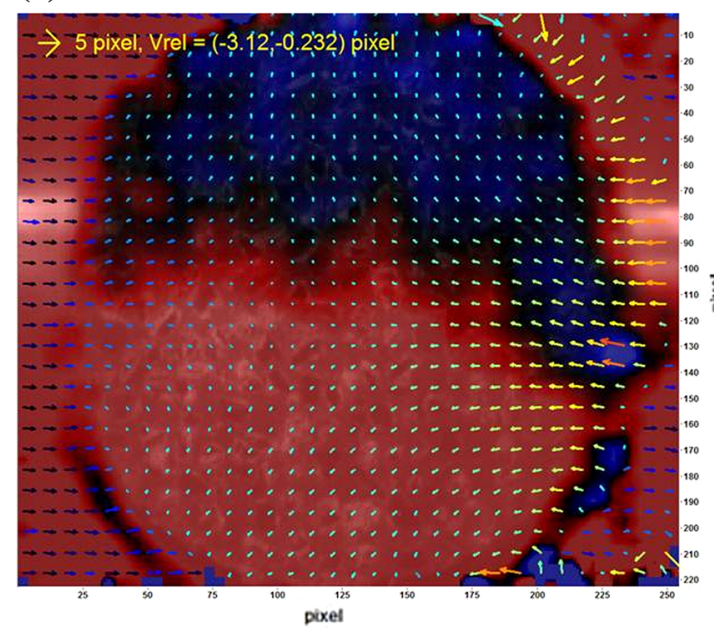

(c)

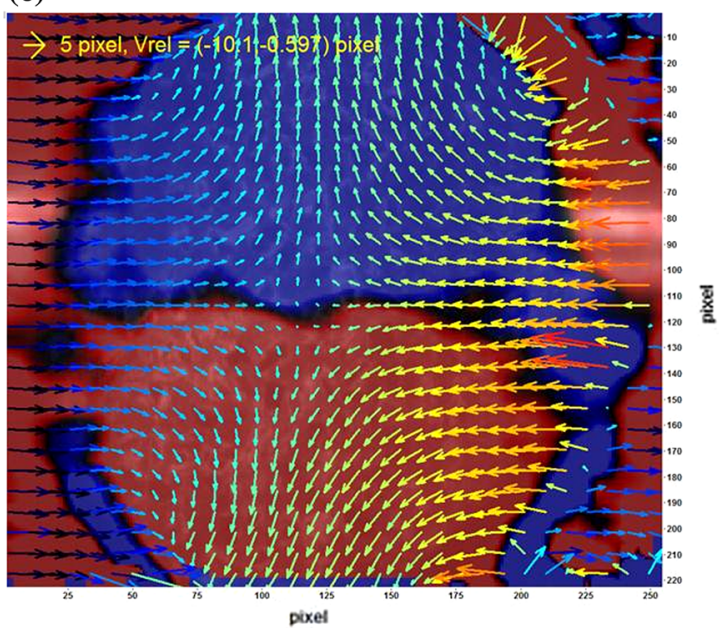

(b)

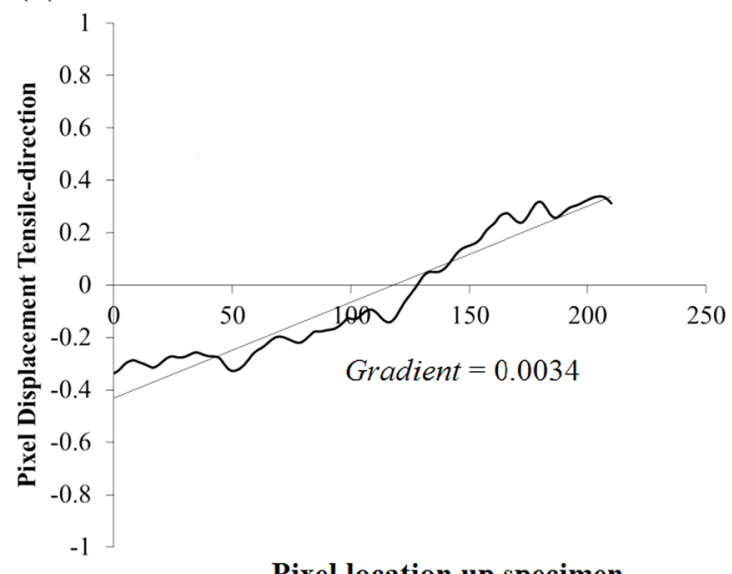

Pixel location up specimen

(d)

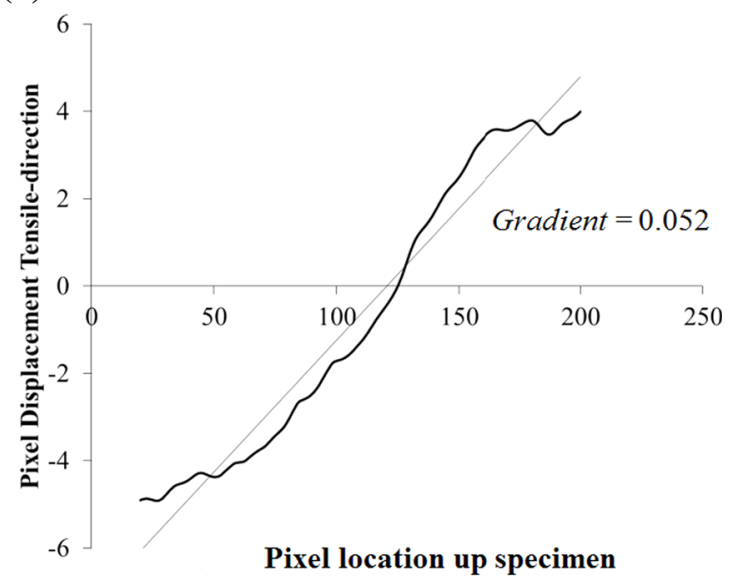

Fig. 8 Representative $\mathbf{a}, \mathbf{c}$ pixel displacement vectors and $\mathbf{b}, \mathbf{d}$ their respective magnitudes plotted in order to determine the average true strain (the slope) calculated in each photograph at $20 \mathbf{a}, \mathbf{b}$ and $130 \mu \mathbf{s}, \mathbf{d}$ during testing

(a)

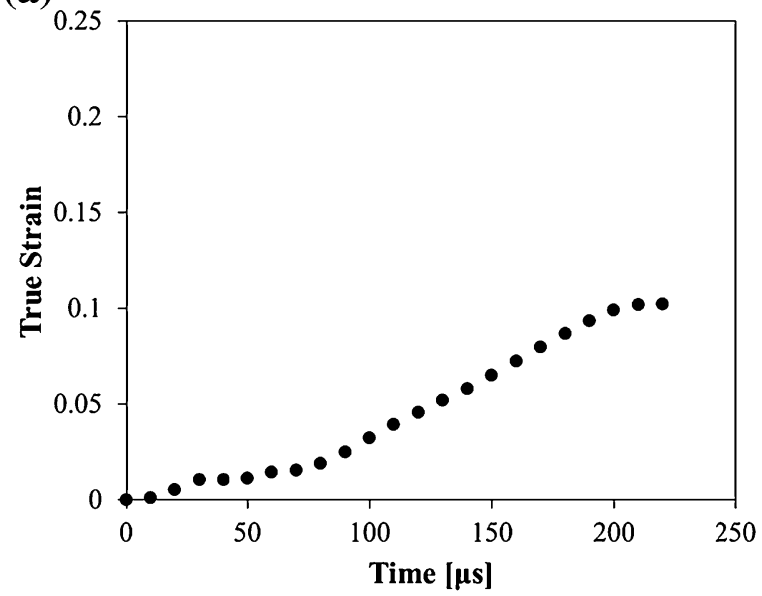

(b)

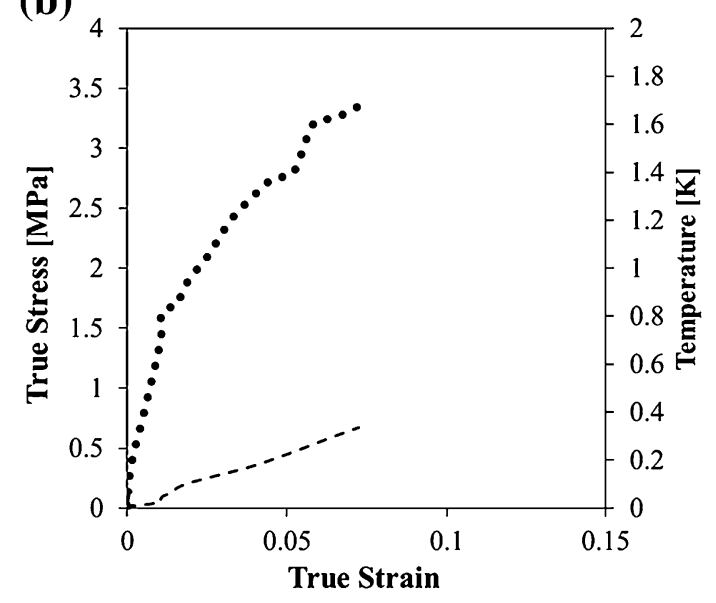

Fig. 9 a Resultant true stain-time curve demonstrating a tensile strain rate of approximately $850 \mathrm{~s}^{-1}$. Each dot on the curve is a true strain value calculated from an image using DIC. b PBS true stress-true strain behavior and theoretical temperature rise at a tensile strain rate of $850 \mathrm{~s}^{-1}$ 


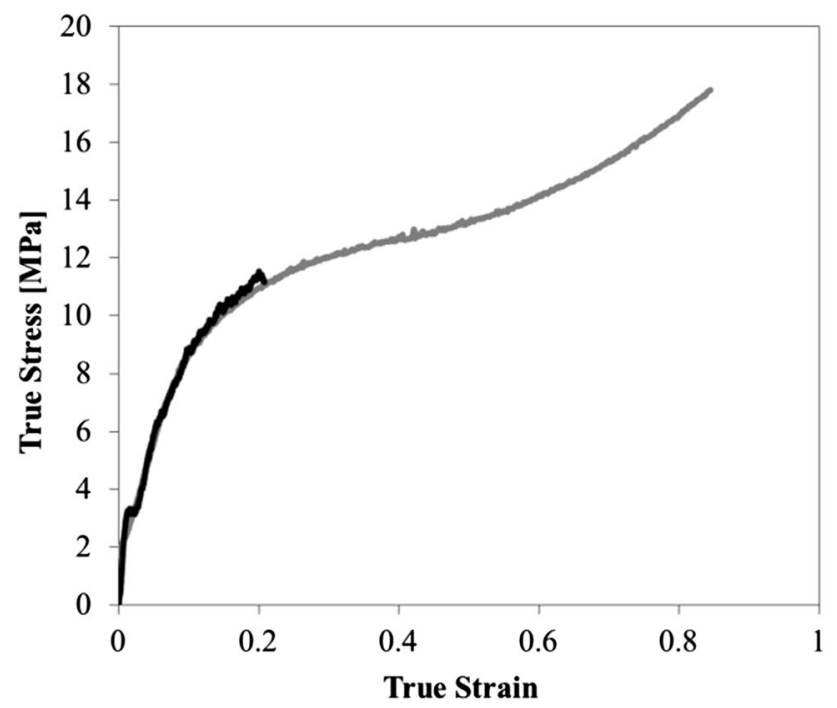

Fig. 10 PBS true stress-true strain behavior in uniaxial compression. Experiment at $1250 \mathrm{~s}^{-1}$ and $20^{\circ} \mathrm{C}$ (black line) and experimental 'simulation' at $-45^{\circ} \mathrm{C}$ and $10^{-2} \mathrm{~s}^{-1}$ (grey line)

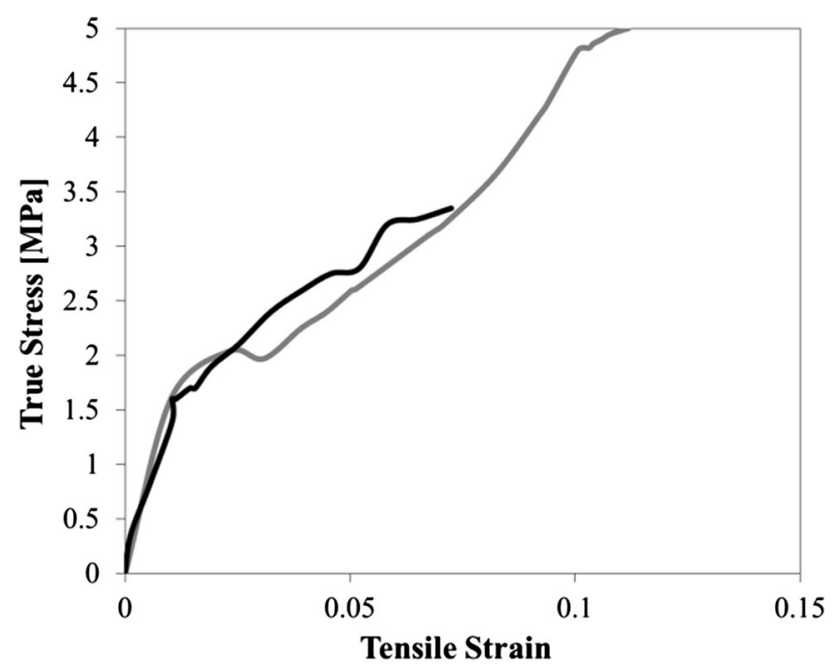

Fig. 11 PBS true stress-true strain behavior in tension. Experiment at $850 \mathrm{~s}^{-1}$ at $20^{\circ} \mathrm{C}$ (black line) and experimental 'simulation' at $-45^{\circ} \mathrm{C}$ at $10^{-6} \mathrm{~m} \mathrm{~s}^{-1}$ (grey line)

simulation method: to predict the high rate behavior of difficult-to-characterize materials (e.g. composites) via low rate deformation and to allow the use of micro-scale imaging tools (e.g. scanning electron microscopes (SEM) and X-ray tomography) to study and better understand the microscopic mechanisms which underpin the high rate response of these materials.

\section{Time-Temperature Equivalence Limitations}

Limitations exist with the use of time-temperature equivalence, which will need to be addressed in future research. Changes in material density are known to affect strength, and this is in turn dependent on temperature [33]. Thermal expansion and contraction caused by thermal changes of the test specimen can also internal stresses which would not be present in specimens tested at room temperature at a different strain rate [3]. When recreating the high rate true stress-true strain response of the tested materials, these changes in density may affect the data obtained, and possibly contribute to the differences between the real high rate data and the simulated data. This complication will need to be further considered in the future. In addition, multiple relaxations within a single polymer may have different dependencies on time and temperature, and it is important to consider carefully which transitions are important over the range of temperatures and strain rates to be investigated.

\section{Conclusions}

The temperature- and rate-dependent behavior of HTPB and PBS were characterized in DMA and compression experiments. High strain rate compression experiments were performed using a recently developed piezoelectric stress measurement system in a split-Hopkinson bar. In addition, tensile experiments were performed on the PBS using the Brazilian testing (indirect tension) technique. At both quasistatic and high strain rates, photography combined with DIC analysis were used to calculate tensile strains in these Brazilian tests. Moreover, the time-temperature simulation technique was used to reproduce the high rate behavior in both tension and compression using quasi-static experiments: excellent agreement between the quasi-static and high strain rate data was shown. The data provide further confidence in the use of time-temperature superposition to indirectly obtain and validate high rate data; a technique which also provides a clear opportunity to better understand high rate behavior of composites using in situ low rate experiments in situ using appropriate microscopic characterization methods.

Acknowledgments The authors would like to thank Dr. J.L. Jordan and Dr. J.R. Foley for their support of the research, and R. Froud and R. Duffin for their ongoing technical support. Effort sponsored by the Air Force Office of Scientific Research, Air Force Material Command, USAF, under grant number FA8655-09-1-3088. The US Government is authorized to reproduce and distribute reprints for Governmental purpose notwithstanding any copyright notation thereon. The authors thank Dr. M. Snyder and Dr. R. Pollak for their ongoing support.

\section{References}

1. Bauwens-Crowet C (1973) The compression yield behaviour of polymethyl methacrylate over a wide range of temperatures and strain-rates. J Mater Sci 8:968-979 
2. Siviour CR, Walley SM, Proud WG, Field JE (2005) The high strain rate compressive behaviour of polycarbonate and polyvinylidene difluoride. Polymer 46:12546-12555

3. Williamson DM, Siviour CR, Proud WG, Palmer SJP, Govier RK, Ellis K, Blackwell P, Leppard C (2008) Temperature-time response of a polymer bonded explosive in compression (EDC37). J Phys D 41:085404

4. Furmanski J, Cady CM, Brown EN (2013) Time-temperature equivalence and adiabatic heating at large strains in high density polyethylene and ultrahigh molecular weight polyethylene. Polymer 54:381-390

5. O'Connell P, McKenna G (1997) Large deformation response of polycarbonate: time-temperature, time-aging time, and time-strain superposition. Polym Eng Sci 37:1485-1495

6. Kendall MJ, Siviour CR (2013) Experimentally simulating adiabatic conditions: approximating high rate polymer behavior using low rate experiments with temperature profiles. Polymer 54:5058-5063

7. Kendall MJ, Siviour CR (2014) Experimentally simulating highrate behaviour: rate and temperature effects in polycarbonate and PMMA. Phil Trans R Soc A 372:20130202

8. Palmer SJP, Field J, Huntley J (1993) Deformation, strengths and strains to failure of polymer bonded explosives. Proc R Soc Lond Ser A 440:399-419

9. Bowden F, Yoffe A (1952) Initiation and growth of explosion in liquids and solids. Cambridge University Press, Cambridge

10. Bowden F, Yoffe A (1958) Fast reactions in solids. Butterworth, London

11. Walley SM, Field JE, Palmer SJP (1992) Impact sensitivity of propellants. Proc R Soc 438:571-583

12. Field JE, Bourne NK, Palmer SJP, Walley SM, Sharma J, Beard BC (1992) Hot-spot ignition mechanisms for explosives and propellants [and Discussion]. Philos Trans R Soc A 339:269-283

13. Swallowe GM, Field JE (1982) The Ignition of a thin layer of explosive by impact; the effect of polymer particles. Proc R Soc A 379:389-408

14. Carneiro F, Barcellos A (1949) Résistance à la traction des bétons. RILEM Bull 13:98-125

15. Awaji H, Sato S (1979) Diametral compressive testing method. J Eng Mater Technol 101:139-147

16. Gray GT, Idar D, Blumenthal W, Cady C, Peterson PD (1998) High-and low-strain rate compression properties of several energetic material composites as a function of strain rate and temperature. In Proceedings of the eleventh international detonation symposium, Office of Naval Research, Snowmass Village, pp 76-84

17. Balzer JE, Siviour CR, Walley SM, Proud WG, Field JE (2004) Behaviour of ammonium perchlorate-based propellants and a polymer-bonded explosive under impact loading. Proc R Soc A 460:781-806

18. Cady CM, Blumenthal WR, Gray G III (2006) Mechanical properties of plastic-bonded explosive binder materials as a function of strain-rate and temperature. Polym Eng Sci $46: 812-819$
19. Siviour CR, Laity PR, Proud WG, Field JE, Porter D, Church PD, Gould PJ, Huntingdon-Thresher W (2008) High strain rate properties of a polymer-bonded sugar: their dependence on applied and internal constraints. Proc R Soc A 464:1229-1255

20. Zhou Z, Chen P, Duan Z, Huang F (2012) Study on fracture behaviour of a polymer-bonded explosive simulant subjected to uniaxial compression using digital image correlation method. Strain 48:326-332

21. Drodge DR, Williamson DM, Palmer SJP, Proud WG, Govier RK (2010) The mechanical response of a PBX and binder: combining results across the strain-rate and frequency domains. J Phys D 43:1-7

22. Williamson DM, Drodge DR, Cullis IG, Gould PJ, Church PD (2010) Towards a fundamental understanding of the thermomechanical response of damaged polymer bonded energetic materials. In: Proceedings of the 14th international symposium on detonation, Office of Naval Research, Coeur d'Alene, pp 1285-1294

23. Drodge D, Williamson DM, Palmer S, Proud W (2012) Strain-rate master curves for a PBX and binder. In: Shock compression of condensed matter, Chicago, vol 1426. AIP Publishing, Melville, New York, pp 653-656

24. Thompson D, DeLuca R, Wright WJ (2012) Time-temperature superposition applied to PBX mechanical properties. In: Shock compression of condensed matter, Chicago, vol 1426. AIP Publishing, Melville, New York, pp 657-660

25. Thompson DG, Deluca R, Brown GW (2012) Time-temperature analysis, tension and compression in PBXs. J Energ Mater 30:299-323

26. Grantham SG, Siviour CR, Proud WG, Field JE, Road M (2004) High-strain rate Brazilian testing of an explosive simulant using speckle metrology. Meas Sci Technol 15:1-4

27. Williamson D, Palmer SJP, Proud WG, Govier R (2009) Brazilian disc testing of a UK PBX approaching the glass transition condition. In: Shock compression of condensed matter, Nashville, vol 1195. AIP Publishing, Melville, New York, p 494-497

28. Gray G III (2000) Classic split-Hopkinson pressure bar testing. In: Kuhn H, Medlin D (eds) ASM handbook: mechanical testing and evaluation, vol 8. ASM International: Materials Park, pp 462-476

29. Gray G III, Blumenthal W (2000) Split-Hopkinson pressure bar testing of soft materials. In: Kuhn H, Medlin D (eds) ASM handbook-mechanical testing and evaluation, vol 8. ASM International, Materials Park, pp 488-496

30. Chen W, Lu F, Zhou B (2000) A quartz-crystal-embedded split Hopkinson pressure bar for soft materials. Exp Mech 40:1-6

31. Kendall MJ, Drodge DR, Froud RF, Siviour CR (2014) Stress gage system for measuring very soft materials under high rates of deformation. Meas Sci Technol 25:075603

32. Sutton MA, Orteu J-J, Schreier HW (2009) Image correlation for shape, motion and deformation measurements. basic conepts, theory and applications. Springer, New York

33. Graff Thompson D, Olinger B, DeLuca R (2005) The effect of pressing parameters on the mechanical properties of plastic bonded explosives. Propellants Explos Pyrotech 30:391-396 